\title{
Modeling of denitrification rates in eutrophic wetlands by artificial neural networks
}

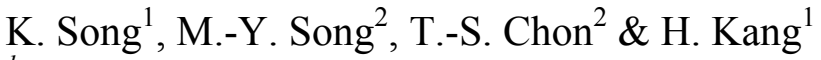 \\ ${ }^{I}$ Department of Environmental Science and Engineering, \\ Ewha Womans University, Seoul, Korea \\ ${ }^{2}$ Division of Biological Sciences, Pusan National University, \\ Busan, Korea
}

\begin{abstract}
Eutrophication can be controlled by denitrification which is complex microbial processes converting nitrate to nitrogen gas in water body. Various environmental factors such as oxygen, available carbon and $\mathrm{pH}$ are known to regulate denitrification rate. However, those controlling variables affect denitrification rates nonlinearly. Further, interactions between those factors hinder a good prediction on the rate. As such, conventional mechanistic modeling of denitrification often fails to fit with data collected from fields.

In this study, we applied artificial neural networks to elucidate complex relationships between denitrification rate and environmental factors. A MultiLayer Perceptron network based on the back-propagation algorithm was utilized for prediction of denitrification rate. High predictability of denitrification was achieved with $R=0.910$ with the trained network. Subsequently, sensitivity analysis was carried out to evaluate factors predominantly controlling denitrification rates. A sensitivity analysis exhibited that DO exert a dominant controlling effect on denitrification rate over other environmental factors.

Keywords: denitrification, eutrophic wetland, artificial neural networks.
\end{abstract}

\section{Introduction}

Aquatic ecosystems near agricultural or urban systems can be polluted by a high loading of nitrogen, which often results in eutrophication in summer season. Since eutrophication causes oxygen depletion, fish kill and odor, many studies 
have focused on economical methods to control eutrophication from nitrogen loading $[1,2]$.

Wetlands, placed between upland and aquatic systems, are known to control eutrophication by removal of $\mathrm{N}$ through various mechanisms including denitrification [3, 4]. Denitrification has been considered as a major mechanism for $\mathrm{N}$ removal, and wetlands are known to be a hotspot of denitrification $[5,6]$. In a wetland where anaerobic conditions are easily introduced, many facultative microorganisms, called denitrifying bacteria, can use nitrate as an electron acceptor and remove the nitrogen from water [5, 7]. High organic matter content, nitrate input and development of rhizosphere with anaerobic condition also induce high denitrification rate [4, 8-10]. Denitrifying Enzyme Activity (DEA) reflects the amount of denitrifying enzymes in soil, and it is often correlated with denitrification rate positively $[6,11]$.

In wetlands, denitrification rates often exhibit extremely high variations both temporally and spatially, due to heterogeneity of environmental conditions. Although many controlling variables of denitrification have already been reported, models for denitrification are still empirically based. Several studies have proposed mechanistic models but they require a large amount of data sets as well as many assumptions [12-15]. As such, conventional modeling often fails to provide a powerful explanation for denitrification in wetlands.

An Artificial Neural Networks' (ANNs) approach based on human brain performance has been applied to various types of ecological data successfully (e.g., [16-19]). In most of the previous studies, ANNs have been applied to biological indicator with environmental factors such as the occurrence of river bird distributions [20], benthic insect species [18], trout density [16], and phytoplankton production [19]. Recently, the applications of ANNs have been accelerated to environmental science. ANNs have been successfully applied to climate change simulation [21], nutrient cycling $[15,22]$ and water quality [2325]. According to the previous studies, ANNs have often shown better predictions for ecological data than classical linear or logistic regression models [20, 26, 27]. A Multi-Layer Perceptron (MLP), which is one of the most popular neural networks, operates under a supervised learning procedure to minimize the errors between the actual and target values based on the back-propagation algorithm $[15,26]$. Sensitivity analysis in neural networks such as the 'Weight' and 'Profile' methods can additionally explain the inter connection weights of each input-hidden-output layer and the responses of the output according to the changes of input variables, respectively [16, 17, 27].

In this study, we aimed 1) to apply ANNs to simulate denitrification rates in the eutrophic constructed-wetland, and 2) to determine key controlling variables for denitrification.

\section{Materials and methods}

\subsection{Mesocosm operation}

To investigate denitrification in eutrophic states in the constructed wetlands, mesocosm-scale wetlands were built at Ewha Womans University in South 
Korea. Wetlands were composed of two types, namely a marsh characterized with shallow water and vegetation, and a pond with deep water without vegetation [1]. We planted 30 Phragmites australis in marsh mesocosm which contains $608 \mathrm{~L}$ of water, while pond was filled with $1301 \mathrm{~L}$ of water. The retention times were ca. 3 days in marsh and $c a .5$ days in pond due to differences in water volume. Contaminated inflow water was prepared by adding ammonia-nitrate $\left(10 \mathrm{mg}^{-\mathrm{N} \mathrm{L}^{-1}}\right)$.

\subsection{Sampling and analysis}

Water and soil samplings and subsequent analyses were conducted once a week for 2 years except winter to early spring seasons. Water temperature, $\mathrm{pH}$ and dissolved oxygen (DO) were measured in situ. Soil samples were collected to $5 \mathrm{~cm}$ depth from the surface in each mesocosm. After removing the large fragments of detritus and roots, all soils were maintained at $4^{\circ} \mathrm{C}$ until analysis of denitrification. Denitrification rate and DEA were determined by an acetylene blocking method. Approximately $10 \mathrm{~g}$ of soil for denitrification and $5 \mathrm{~g}$ for DEA with glucose and nitrate were placed in a $100 \mathrm{ml}$ sterilized glass vial and incubated for $20 \mathrm{~min}$ with oxygen-free $\mathrm{N}_{2}$ gas purge at $20^{\circ} \mathrm{C}$. After acetylene $(10 \%, \mathrm{v} / \mathrm{v})$ addition in the head space, cumulative nitrous oxide concentration in head space collected within 2 hours was measured by gas chromatography equipped with ECD (HP-6890) [28].

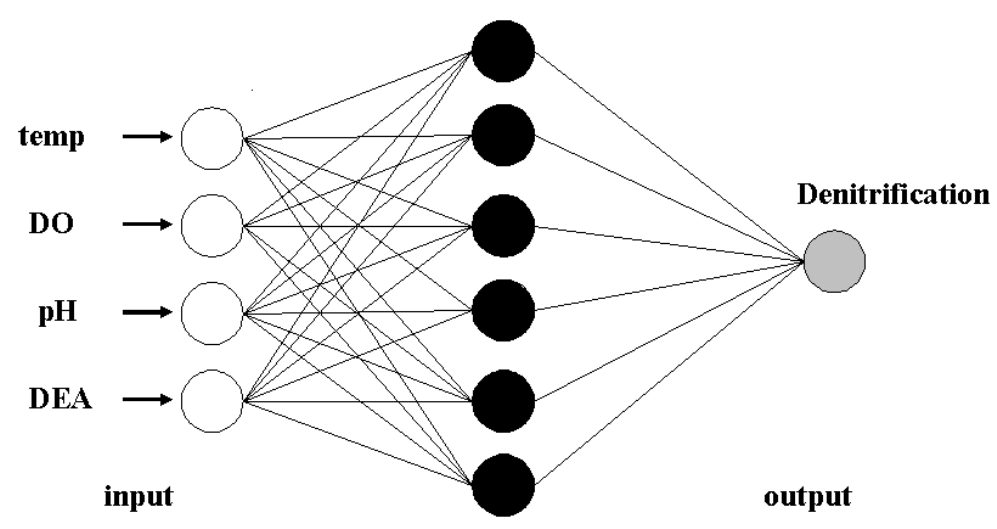

hidden layer

Figure 1: Conceptual structure of MLP used for predicting denitrification (modified from [17, 29]).

\subsection{Application of Artificial Neural Networks}

Basic structure of MLP in this study was present in Fig. 1. Water temperature $\left({ }^{\circ} \mathrm{C}\right)$, DO $\left(\mathrm{mg} \mathrm{L}^{-1}\right), \mathrm{pH}$ and DEA were chosen as input data (4 nodes). Denitrification rate was used as an output (1 node). In this study, 6 hidden 
neurons were chosen for the learning procedure, and iteration was performed 3000 times. For training the momentum ( 0.95 in this study) was used for the learning procedure, while the learning rate was initially set to 0.75 and was gradually decreased as convergence was achieved. The trained MLP was tested by the 'leave one out' method using MATLAB ver.6.1. For sensitivity analysis, the 'Weight' and 'Profile' methods were used [16, 27]. The 'Weight' method involves the weight calculations in hidden-output neuron connections during the whole iteration procedure. The 'Profile' method considers the influence of the certain variations of each input variables between minimum and maximum values while the remaining input variables are fixed [16].

\section{Results}

\subsection{Mesocosm operation}

Table 1 presents the environmental characteristics and denitrification in wetlands from May, 2004 to November, 2005. Water temperature varied between 2.5 and $28.1^{\circ} \mathrm{C}$ while the median value was $22.7^{\circ} \mathrm{C}$ during the observation period. $\mathrm{pH}$ in wetlands was neutral and slightly alkaline ranging $6.3-9.8$ with the median value of 7.0. The $\mathrm{pH}$ peaked in June, 2004 and 2005 in concomitant with algal blooming. DO ranged between 0.4 to $9.8 \mathrm{mg} \mathrm{L}^{-1}$. DO was dropped to 0.4 on August, 2005, while the highest value was recorded in May, 2005 (Fig. 2). Denitrification rates showed high variations from 0.3 to $1559.6 \mathrm{ng} \mathrm{N}_{2} \mathrm{O} \mathrm{hr} \mathrm{g}^{-1}$. Denitrification rates exhibited the highest in July while it was the lowest in the spring and early winter. The median value of DEA was $4072 \mathrm{ng} \mathrm{N} \mathrm{O} \mathrm{hr}^{-1} \mathrm{~g}^{-1}$.

Table 1: Environmental characteristics and denitrification rate in the eutrophic constructed-wetlands during the whole operation period in 2004 and 2005 .

\begin{tabular}{l|ccc}
\hline & Median & Min. & Max. \\
\hline Temp $\left({ }^{\circ} \mathrm{C}\right)$ & 22.7 & 2.5 & 28.1 \\
DO $\left(\mathrm{mg} \mathrm{L}^{-1}\right)$ & 4.3 & 0.4 & 12.3 \\
pH & 7 & 6.3 & 9.8 \\
DEA $\left(\right.$ ng N $\left._{2} \mathrm{O} \mathrm{h}^{-1} \mathrm{~g}^{-1}\right)$ & 4072 & 7.3 & 16261 \\
$\left.\begin{array}{l}\text { Denitrification rate } \\
(\text { ng N }\end{array} \mathrm{O} \mathrm{h}^{-1} \mathrm{~g}^{-1}\right)$ & 18.2 & 0.3 & 1559.6 \\
\hline
\end{tabular}

\subsection{Application of ANNs}

The MLP showed high predictability after training. The estimated and observed values were correlated with $R=0.910(\mathrm{P}<0.001)$ after 3000 iterations based on the test of the 'leave one out' method (Fig. 3). 


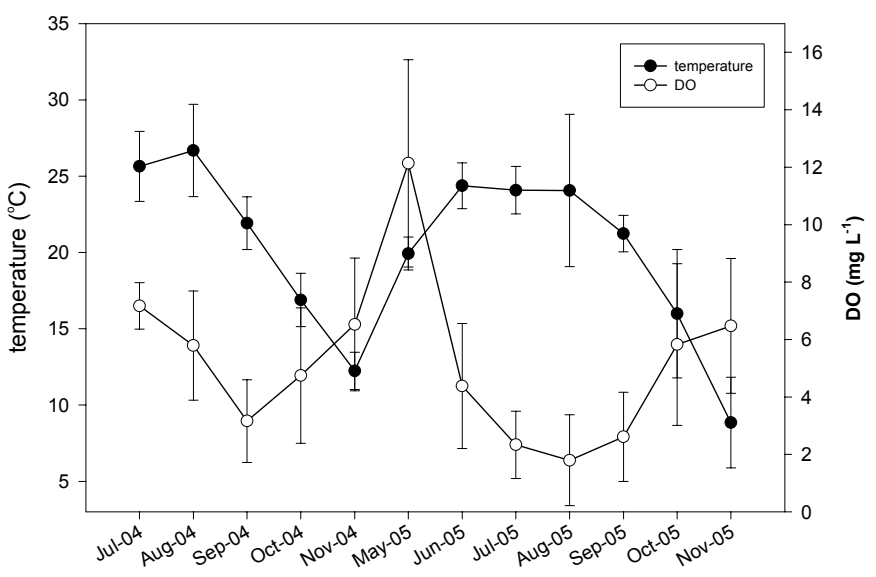

Figure 2: Seasonal variations of averaged temperature and DO during the wetland operation period. The data chosen as input for the MLP training are exhibited.

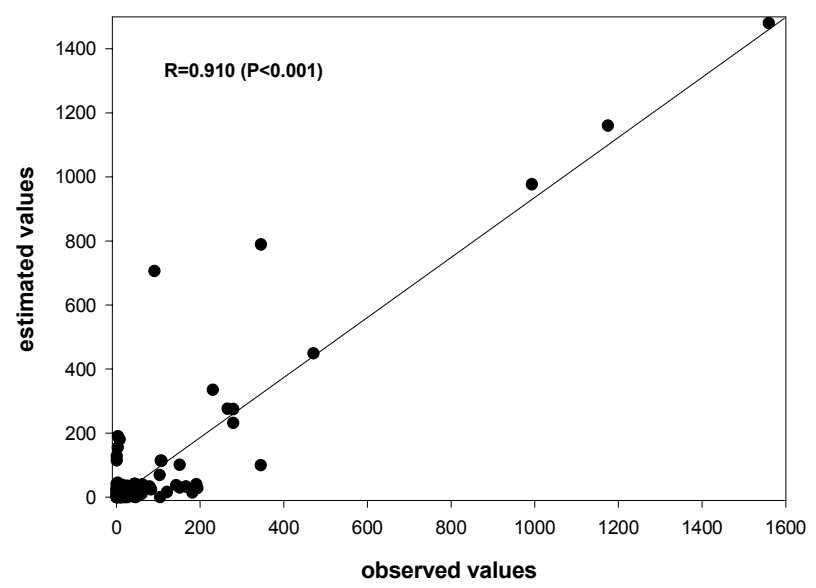

Figure 3: Estimated and observed values tested by MLP using the 'leave one out' method $(n=95)$. The solid line represents the $1: 1$ between estimated and observed values.

In order to elucidate the importance of input variables, sensitivity analyses based on 'Weight' and 'Profile' were carried out. According to the 'Weight' analysis, DO was the predominant factor being followed by $\mathrm{pH}$, while temperature and DEA weakly contributed to determination of denitrification. Percents of contribution of $\mathrm{DO}$ and $\mathrm{pH}$ were $45 \%$ and $30 \%$, respectively, whereas percents of contribution of temperature and DEA were $c a$. $10 \%$ for both factors (Fig. 4). Fig. 5 shows the contribution profile of the input variables in determining changes in denitrification according to the 'Profile' analysis. The 
degree of contribution of Oxygen to denitrification decreased monotonically along with the increase in the levels of Oxygen. In contrast, the degree of contribution of $\mathrm{pH}$ increased rapidly until $\mathrm{pH}$ reached the middle range. From the middle point on, contribution of $\mathrm{pH}$ remained in the same range.

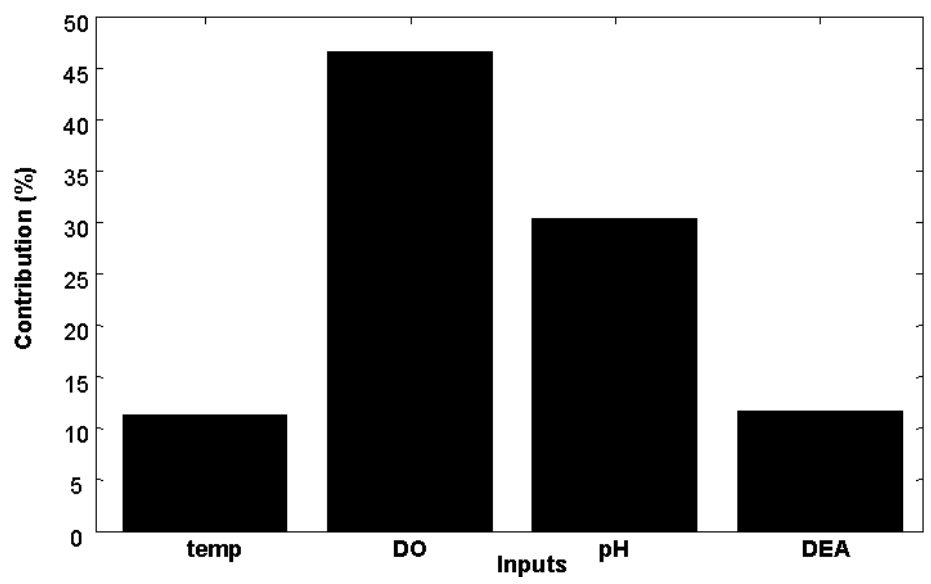

Figure 4: Relative contribution of input variables according to the 'Weight' sensitivity analysis.

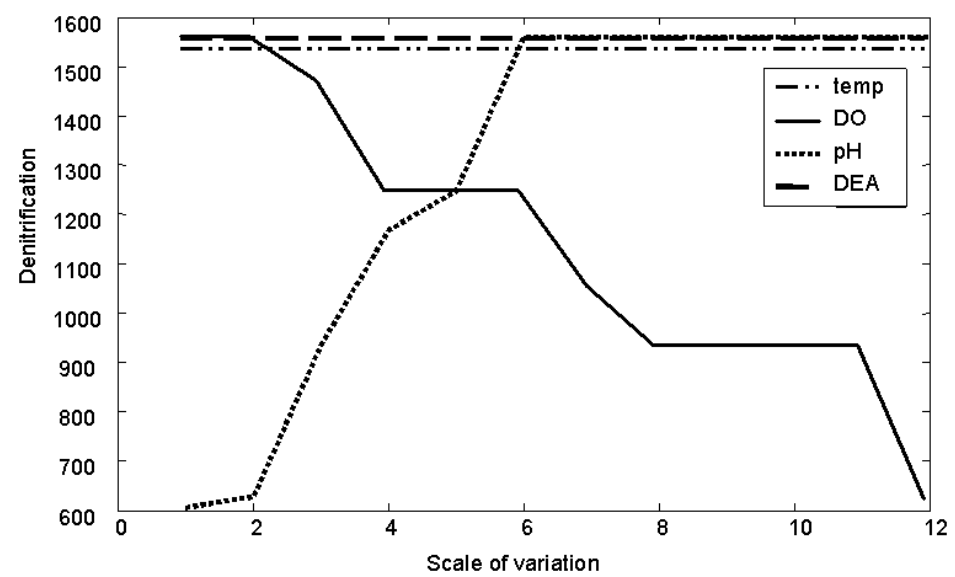

Figure 5: Contribution profile over the scale of the different input variables in determining changes in denitrification.

\section{Discussion and conclusion}

High predictability of denitrification in eutropic wetlands was achieved with the trained artificial neural networks. This study demonstrated that MLP could be efficiently utilized for analyzing complexity residing in the data related to eutropic states in wetlands. 
The sensitivity analyses could provide a comprehensive view on the overall scope of input-output relationships (i.e., profile) representing the whole network procedure and specific information on the degree of contribution (i.e., weight) according to local changes in the input variables as well [16]. According to the 'Weight' analysis, DO and $\mathrm{pH}$ predominantly contributed to changes in denitrification (Fig. 4), whereas contribution of the other input variables was minimal. The results were coincident with the results from the 'Profile' method. Denitrification exhibited steep changes according to the changes in $\mathrm{DO}$ and $\mathrm{pH}$ (Fig. 5). The high contribution of DO could be explained from the fact that denitrification may be discernable when DO is low, regarding that denitrification would be strongly inhibited under high DO levels [30, 31].

The result of $\mathrm{pH}$ on the 'Profile' analysis demonstrated that denitrification might be inhibited under low $\mathrm{pH}$ but will be stimulated along with the increase in $\mathrm{pH}$. However, this positive relation between $\mathrm{pH}$ and denitrification became constant from middle range of $\mathrm{pH}$ since neutral or slightly alkaline conditions were in the optimum range for denitrification $[4,32]$. Some researchers reported that denitrification decreased in acidic condition [33] while denitrification is facilitated in alkaline condition [34, 35]. Considering these reports, denitrification would not be further enhanced over the optimum range of $\mathrm{pH}$, while denitrification would greatly increase as $\mathrm{pH}$ increased from low to medium values. The results from our study confirmed the reports in previous studies on the relationships between $\mathrm{pH}$ and denitrification.

The low contribution of temperature shown in the sensitivity analyses (Figs. 4 and 5), on the other hands, implies that temperature might not be a key variable in controlling the states of denitrification in the eutrophic wetlands tested in this study. This low contribution of temperature can be explained as follows. Firstly, we did not consider the condition of highly low temperatures in winter for this study. Generally, denitrification ceased below $5^{\circ} \mathrm{C}$, while it increased with higher levels of temperature $[30,33,36]$. However, temperatures measured in this study were in the narrow range because we only operated the wetlands from late spring to autumn (for 2 years) (Fig. 2). Since the input data only covered the given range, the 'Weight' and 'Profile' sensitivity methods could not reveal the effect of temperature beyond the range of temperatures used for the test in this study. Secondly, the effect of temperature in previous studies might be over-estimated. Some researchers reported the highest denitrification rate in winter [37, 38]. The reviews of $\mathrm{Q}_{10}$ of the treatment wetlands near 1.0 [3,39] exhibited that temperature effect can be estimated to be too high. The effect of temperature was also often confounded with other seasonal effects [6, 39] involving light intensity, vegetation growth, etc. Therefore, low contribution of temperature in the limited range indicates that denitrification is not highly sensitive to seasonal variables such as DOC supply, microbial activity or plant growth in this study. It indicates that substrates $[8,40]$ for denitrification could not be limited in our wetlands due to eutrophication. Eutrophication was also influential in keeping DEA from contributing to denitrification. DEA is highly dependent on nitrate and carbon availability $[6,10]$. However, the nutrient sources such as nitrate or carbon could not be a limiting factor in eutrophication. Consequently, 
denitrification could not be influenced by DEA in the eutrophic wetlands tested in this study.

In summary, denitrification in mesocosm-scale eutrophic wetlands was well predicted using the trained MLP. The results of sensitivity analysis exhibited that, under the condition of the limited range in temperature, DO and $\mathrm{pH}$ exert a dominant controlling effect on denitrification rate over other environmental factors in this study. In addition, the sensitivity analysis such as the 'Profile' and 'Weight' methods appeared to be useful for understanding both the overall scope of the environment-denitrification relationships and specific information on local contribution of input variables in determining denitrification. The results of this study suggest ANNs could be a powerful modeling tool to explain complexity residing in ecological data.

\section{Acknowledgements}

This subject is supported by Ministry of Environment as The Eco-Technopia 21 project and Advanced Environmental Biotechnology Research Center.

\section{References}

[1] Mitsch W.J. Mitsch R.H., \& Turner R.E., Wetlands of the old and new worlds: ecology and management. In Mitsch, W.J. (ed), Global Wetlands: Old World and New. Elsevier Science, pp. 3-56. 1994.

[2] Rezania T., Cicek N. \& Oleszkiewicz, J.A., Kinetics of hydrogendependent denitrification under varying $\mathrm{pH}$ and temperature conditions. Biotechnology and Bioengineering 92, pp. 900-906. 2005.

[3] Kadlec R.H \& Knight R.L., Treatment wetlands, CRC/Lewis Publishers, Boca Raton, FL. 1996.

[4] Mitsch W.J \& Gosselink J.G., Wetlands. John Wiley and Sons Inc; New York, pp. 107-118. 2000.

[5] Reddy K.R \& D’Angelo E.M., Soil Processes regulating water quality in wetlands. In Mitsch, W.J. (ed), Global Wetlands: Old World and New. Elsevier Science, pp. 309-324. 1994.

[6] White J.R \& Reddy K.R., Influence of nitrate and phosphorus loading on denitrifying enzyme activity in Everglades wetland soils. Soil Science Society of America Journal 63, pp. 1945-1954. 1999.

[7] Zumft, W.G., Cell biology and molecular basis of denitrification. Microbiology and Molecular Biology Reviews 61, pp. 533-616. 1997.

[8] Brix H., 1997. Do macrophytes play a role in constructed treatment wetlands? Water Science and Technology 35, pp. 11-17. 1993.

[9] Groffman P.M. \& Hanson G.C., Wetland denitrification: Influence of site quality and relationships with wetland delineation protocols. Soil Science Society of America Journal 61, pp. 323-329. 1997.

[10] Hume N.P. \& Fleming M.S., Horne A.J., Denitrification potential and carbon quality of four aquatic plants in wetland microcosms. Soil Science Society of America Journal 66, pp. 1706-1712. 2002. 
[11] Smith M.S \& Tiedje J.M., Phases of denitrification following oxygen depletion in soil. Soil Biology and Biochemistry 11, pp. 261-267. 1979.

[12] Halling-Sørensen B. \& Nielsen S.N., A model of nitrogen removal from waste water in a fixed bed reactor using simultaneous nitrification and denitrification (SND). Ecological Modelling 87, pp. 131-141. 1996.

[13] Heinen M. Simplified denitrification models: Overview and properties. Geoderma, in press. 2005a.

[14] Heinen M. Application of a widely used denitrification model to Dutch data sets. Geoderma, in press. 2005 b.

[15] Holmberg M., Forsius M., Starr M. \& Huttunen M. An application of artificial neural networks to carbon, nitrogen and phosphorus concentrations in three boreal streams and impacts of climate change. Ecological Modelling 195, pp. 51-60. 2006.

[16] Gevrey M., Dimopoulos I. \& Lek S., Review and comparison of methods to study the contribution of variables in artificial neural network models. Ecological Modelling 160, pp. 249-264. 2003.

[17] Lek S., Delacoste M., Caran P., Dimopoulos I., Lauga J. \& Aulagnier S., Application of neural networks to modelling nonlinear relationships in ecology. Ecological Modelling 90, pp. 39-52. 1996.

[18] Park Y.S, Ce're'ghino R., Compin A. \& Lek S., Applications of artificial neural networks for patterning and predicting aquatic insect species richness in running waters. Ecological Modelling 160, pp. 265-280. 2003.

[19] Scardi M., Artificial neural networks as empirical models for estimating phytoplankton production. Marine Ecology Progress Series 139, pp. 289-299. 1996.

[20] Manel S., Dias J-M \& Ormerod S.J. Comparing discriminant analysis, neural networks and logistic regression for predicting species distributions: a case study with a Himalayan river bird. Ecological Modelling 120, pp. 337-347. 1999.

[21] Seginer, I., Boulard T. \& Bailey B.J., Neural network models of the greenhouse climate. Journal of Agricultural Engineering Research 59, pp. 203-216. 1994.

[22] Melesse AM. \& Hanley RS., Artificial neural network application for multi-ecosystem carbon flux simulation. Ecological Modelling, 189, pp. 305-314. 2005.

[23] Nour M.H., Smith D.W., El-Din M.G. \& Prepas E.E., The application of artificial neural networks to flow and phosphorus dynamics in small streams on the Boreal Plain, with emphasis on the role of wetlands. Ecological Modelling 191, pp. 19-32. 2006.

[24] Acharya C., Mohanty S., Sukla L.B. \& Misra V.N., Prediction of sulphur removal with Acidithiobacillus sp. using artificial neural networks. Ecological Modelling 190, pp. 223-230. 2006.

[25] Karakitsios S.P., Papaloukas C.L., Kassomenos A. \& Polodis G.A., Assessment and prediction of benzene concentrations in a street canyon using artificial neural networks and deterministic models: Their response to "what if" scenarios . Ecological Modelling 193, pp. 253-270. 2006. 
[26] Lek S. \& Guégan J.F., Artificial neural networks as a tool in ecological modeling, an introduction. Ecological Modelling 120, pp. 65-73. 1999.

[27] Özemi S.L, Tan C.O. \& Özemi U., Methodological issues in building, training, and testing artificial neural networks in ecological applications. Ecological Modelling 195, pp. 83-93. 2006.

[28] Beauchamp E.G. \& Bergstrom D.W., Denitrification. In Carter M.R. (ed), Soil Sampling and Methods of Analysis. Lewis Publishers, pp. 351-355.

[29] Goh A.T.C., Back-propagation neural networks for modeling complex systems. Artificial Intelligence in Engineering 9, pp. 143-151. 1995.

[30] Richardson W., Strauss, E., Bartsch L., Monroe E., Cavanaugh J., Vingum L. \& Sovalle D., Denitrification in the upper Mississippi River: rates, controls, and contribution to nitrate flux. Canadian journal of fisheries and aquatic sciences. 61, pp. 1102-1112. 2004.

[31] Sirivedhin T. \& Gray K.A., Factors affecting denitrification rates in experimental wetlands: Field and laboratory studies. Ecological Engineering 26, pp. 167-181. 2006.

[32] Etherington J.R., Wetland Ecology. Edward Arnold, London. p.67. 1983.

[33] Bremner A.M., Shaw R.L. \& Macalady D.L., Denitrification in soil. Factors affecting denitrification. Journal of Agricultural Science 51, pp. 40-52. 1954.

[34] Ellis, S., Howe, M.T., Goulding K.W.T., Mugglestone, M.A. \& Dendooven, L., Carbon and nitrogen dynamics in a grassland soil with varying $\mathrm{pH}$ : Effect of $\mathrm{pH}$ on the denitrification potential and dynamics of the reduction enzymes. Soil Biology and Biochemistry 30, pp. 359-367. 1998.

[35] Simek M. \& Hopkins D.W., Regulation of potential denitrification by soil $\mathrm{pH}$ in long-term fertilized arable soils. Biology and Fertility of Soils 30, pp. 41-47. 1999.

[36] Stanford G., Dzienia S., \& Van der Pol R., Effect of temperature on denitrification rate in soils. Journal of Soil Science Society of America 39, pp. 867-870. 1975 .

[37] Hasegawa T. \& Okino T., Seasonal variation of denitrification rate in Lake Suwa sediment. Limnology 5, pp. 33-39. 2004.

[38] Pinay, G., Roques, L. \& Fabre, A., Spatial and temporal patterns of denitrification in a riparian forest. Journal of Applied Ecology 30, pp. 581-591. 1993.

[39] Bachand P.A.M. \& Horne, A.J., Denitrification in constructed free-water surface wetlands: Effects of vegetation and temperature. Ecological Engineering 14, pp. 17-32. 2000.

[40] Platzer C., Enhanced nitrogen elimination in subsurface flow artificial wetlands- a multi stage concept. Preprints of the $5^{\text {th }}$ International Conference on Wetland Systems for Water Pollution Control. University für Bodenkultur Wien. Vienna, Austria. pp. 1-8. 1996. 